\title{
O CONHECIMENTO DAS IMAGENS POPULARES: PSICOLOGIA SOCIAL E EXPERIÊNCIA ESTÉTICA NOS CONSTRUTORES E ARQUITETURAS FANTÁSTICAS ${ }^{1}$
}

\author{
THE KNOWLEDGE OF POPULAR IMAGES: \\ SOCIAL PSYCHOLOGY AND AESTHETIC EXPERIENCE \\ IN FANTASTIC BUILDERS AND ARCHITECTURES
}

\author{
Arley Andriolo ${ }^{2}$ \\ (Instituto de Psicologia - Universidade de São Paulo) \\ a.a.andriolo@gmail.com
}

Recibido: $15 / 05 / 2018$

Aprobado: 11/07/2018

\begin{abstract}
RESUMO
O reconhecimento de objetos produzidos pelas classes populares como objetos de arte corresponde a um processo histórico situado entre os séculos XIX e XX. Aqueles objetos foram qualificados por termos como "revolucionário" e "anticapitalista”. Dentre as obras arquitetônicas, surgiram imagens inventivas e fantásticas, as quais concentram um problema acerca do conhecimento das imagens populares. O estudo dessa questão situa-se em dois campos entrecruzados: 1) o campo artístico, com seu habitus e suas regras; 2) o campo do folclore, com suas regras próprias. Em ambos, o conhecimento da imagem está limitado, pois não se discute o significado próprio da experiência e do seu imaginário originário. Este artigo procura examinar essa questão, cujo resultado é a proposição de três elementos fundamentais para o conhecimento da imagem, nos termos de arte, imaginação e experiência estética.
\end{abstract}

Palavra-Chave: Psicologia Social da Imagem; Arte Popular; Arte e Sociedade; Estética Social

\section{ABSTRACT}

The recognition of the objects produced by popular class members as art objects corresponds to a historical process between the XIXth and the XXth centuries. Those objects were considered regarding their qualities as "revolutionary" and "anti-capitalist." Among the architectural works, there were creative and fantastic images which concentrate a problem on the knowledge of popular images. The study of this question lies in two interconnected fields: 1) the artistic field, with its habitus and its rules; 2) and the field of folklore, with its own rules. In both, the knowledge of the image is limited because the proper meaning of the experience and its original imaginary are not discussed. This article seeks to examine this

\footnotetext{
${ }^{1}$ Esta pesquisa contou com dados coletados em visita de estudos à França. Naquele momento, contou com a orientação do prof. João Frayze-Pereira e as indicações da Profa. Annateresa Fabris. Financiamento da Fundação de Amparo à Pesquisa do Estado de São Paulo.

${ }^{2}$ Professor Associado Departamento de Psicologia Social e do Trabalho do Instituto de Psicologia da Universidade de São Paulo, onde é coordenador do Laboratório de Estudos em Psicologia da Arte. Bacharel e licenciado em História (FFLCH e FE-USP), Doutor em Psicologia Social (IP-USP), recebeu o título de Livre-Docência em 2014, com a tese A transformação do mundo em pintura: estudos em psicologia social do fenômeno das imagens. Orientador do Programa de pós-graduação em Psicologia Social (IP-USP), junto à linha de pesquisa "Psicologia Social de Fenômenos Histórico-Culturais Específicos", na subárea "Percepção e experiência estética na vida social”. Conforme abordagem em fenomenologia social, seus projetos são dedicados à compreensão das imagens, da estética e da arte na vida social.
} 
question, and the result is a proposition of three fundamental elements of the image knowledge, concerning art, imagination and aesthetic experience.

Keywords: Social Psychology of the Image; Popular Art; Art and Society; Social Aesthetics

\section{Introdução}

Joseph Ferdinand Cheval (1836-1924) era carteiro na região francesa do Drôme, na França, entre Grenoble e Valence, quando, em junho de 1879, iniciou a longa jornada de construção de um palácio no terreno do fundo de sua casa, em Hauterives. Tinha 43 anos naquele momento. As origens desse impulso são incertas, ora voltadas para as pedras coletadas pelos caminhos, as quais lhe chamaram a atenção para novas formas, ora para um sonho que lhe incitara tal missão. A conclusão da tarefa ocorreu cerca de trinta e três anos depois. O templo seria a última morada do carteiro se os poderes municipais não tivessem intervindo contra seu intento. Como essa determinação da municipalidade deu-se antes de sua morte, Cheval encontrou forças para erigir um pequeno palácio no cemitério local, no qual seu corpo descansou.

Reunidos pedaços de pedras e outros materiais coletados pelos caminhos, por meio do trabalho de pedreiro, o carteiro ergueu com cimento uma edificação de paredes espessas, repleta de formas e esculturas simbólicas, animais, monstros, homens e mulheres. O Palais Idéal, como foi chamado, abrese em estreitos corredores e passagens ladeados de paredes sobre as quais frases e dizeres instruem os visitantes. A grande fachada é protegida por três gigantes guardiões: César, Vercingéntorix e Arquimedes.

A edificação atraiu a atenção de muitos artistas e intelectuais, particularmente de surrealistas como André Breton (1896-1966), que lá esteve no ano de 1931, e também, dedicando-lhe algumas páginas de seu "Message Automatique", dois anos depois. Breton reconhecia na manifestação de Cheval a origem de processos criativos a serem situados junto a seu manifesto do surrealismo. Trata-se de construção marcante em sua suntuosidade e elementos iconográficos proveniente do imaginário popular oitocentista, mas que, como notou Delacampagne (1989), não recebeu grande atenção das autoridades.

Apenas no ano de 1969, o Palácio Ideal foi elevado à condição de monumento, inscrito no livro do patrimônio francês. Tornado patrimônio histórico, converteu-se em destino turístico, se não dos mais visitados, ao menos ganhou um lugar nos mapas e roteiros. O vilarejo recebeu um escritório de turismo, a classificação como “ville botanique” e uma galeria de artistas “marginais”, chamada L'Art en Marche.

A contrapartida ao reconhecimento desse monumento veio da própria intelectualidade francesa. Alguns estudiosos observaram com desconfiança o aparecimento dessas obras oriundas de criadores populares em condições extrínsecas ao campo artístico. O embate mais elucidativo dessa questão, provavelmente, teve origem na crítica de Pierre Bourdieu (1930-2002) à noção de Art Brut, para quem o reconhecimento de algo como "de arte" é um arbitrário social que, ao mesmo tempo em que se impõe como verdade, oculta seu processo histórico e conflituoso de formação. Para a teoria do habitus, a localização dos criadores brutos se dá tão-somente no olho do crítico que os reconhece como tal. Nesse sentido, seria inapropriado falar-se em "arte popular”, "arte ingênua” ou "arte bruta”, porque não representariam senão uma determinação exterior.

Como o habitus de classe reproduz-se através da educação, a produção de obras por classes desprovidas total ou parcialmente de capital cultural tenderia a reproduzir esquemas simplificados da chamada arte culta. Os autodidatas que, por inclinação pessoal, passam a dedicar-se à produção de obras de arte, o fariam segundo esses esquemas provenientes das classes dominantes, a eles acessíveis pelo sistema educacional. O sociólogo exemplifica esse ponto por meio do Palácio de Ferdinand Cheval, "imagem da cultura pequeno-burguesa”, "feérica de folhetim saída das gravuras da Veillée des Chaumières com seus labirintos e suas galerias, suas grotas e cascatas” (Bourdieu, 1979, p. 380; tradução livre). 
Noutra passagem, em seu As regras da arte, Bourdieu (1996) mirou diretamente a Art Brut - "uma espécie de arte natural que só existe como tal por um decreto arbitrário dos mais refinados” - e seus teóricos, Thévoz (1936- ) e Cardinal (1940- ), nos seguintes termos:

\begin{abstract}
por uma espécie de contra-senso absoluto, senão porque ignoram que elas só podem aparecer como tais para um olho produzido, - como o deles - , pelo campo artístico, logo, habitado pela lógica desse campo: é toda a história do campo artístico que determina (ou torna possível) a tentativa essencialmente contraditória e necessariamente condenada ao fracasso pela qual visam constituir artistas contra a definição histórica do artista. (Bourdieu, 1996, p. 277).
\end{abstract}

Com relação ao Palácio Ideal, o filósofo Christian Delacampagne (1989, p. 8) rebateu essa crítica, dizendo que faltava a Bourdieu uma dimensão daquele monumento: "ele não vê como tal obra se constitui numa criação subversiva, abrindo uma brecha nos conformismos arquiteturais e artísticos”. E Michel Thévoz (1997), em resposta ao ataque frontal, indaga se não seria o argumento do sociólogo, ele próprio, tautológico, dizendo:

\title{
A lógica formal jamais traiu melhor sua incongruência que aplicada à arte. A prova do pudim, dizia Engels, é que a ele se come; a prova da Art Brut é que a ela se vê, prova também que a contradição está no princípio da criação simbólica. Acreditara-se compreender que, de um ponto de vista ético ou político, Pierre Bourdieu estigmatizava a transmissão hereditária do capital cultural... (Thévoz, 1997, p. 7; tradução livre)
}

Há diversos níveis de problemas expostos nesse debate, os quais, no limite, remetem à existência social de coisas, ou a coisas que não existem socialmente, ou seja, do reconhecimento conferido aos objetos e saberes oriundos da experiência das classes populares. Como intervenção situada no campo da psicologia social, dentre os diversos níveis, circunscreverei neste artigo o problema que me parece mais evidente nessa discussão que trata da experiência estética de gente comum. Para tanto, considere-se, de imediato, o problema da formação do campo artístico, com suas regras e habitus, do qual resulta um discurso sobre a arte conforme regras de distinção, como queria Bourdieu.

O reconhecimento artístico de manifestações, tais como esta de Cheval, situa-se em dois campos entrecruzados. Por um lado, a formação do campo artístico, do ponto de vista sociológico, com seu habitus e suas regras restritos aos membros do campo, a partir do século XIX, opera sobre uma distinção entre artes maiores e menores, a qual resultou na proposição de uma "arte popular" circunscrita no campo do folclore. Por outro lado, os objetos de valor artístico provenientes das classes populares não dizem respeito apenas às categorias do campo artístico ou do folclore, mas revelam um conhecimento sensível próprio da experiência e do imaginário desses grupos sociais. O problema a ser examinado neste artigo situa-se nesse debate acerca do estudo das imagens populares, manifestas em objetos limítrofes ao campo artístico, cujo resultado será a proposição de três elementos fundamentais para o conhecimento em psicologia social, nos termos de arte, imaginação e experiência estética.

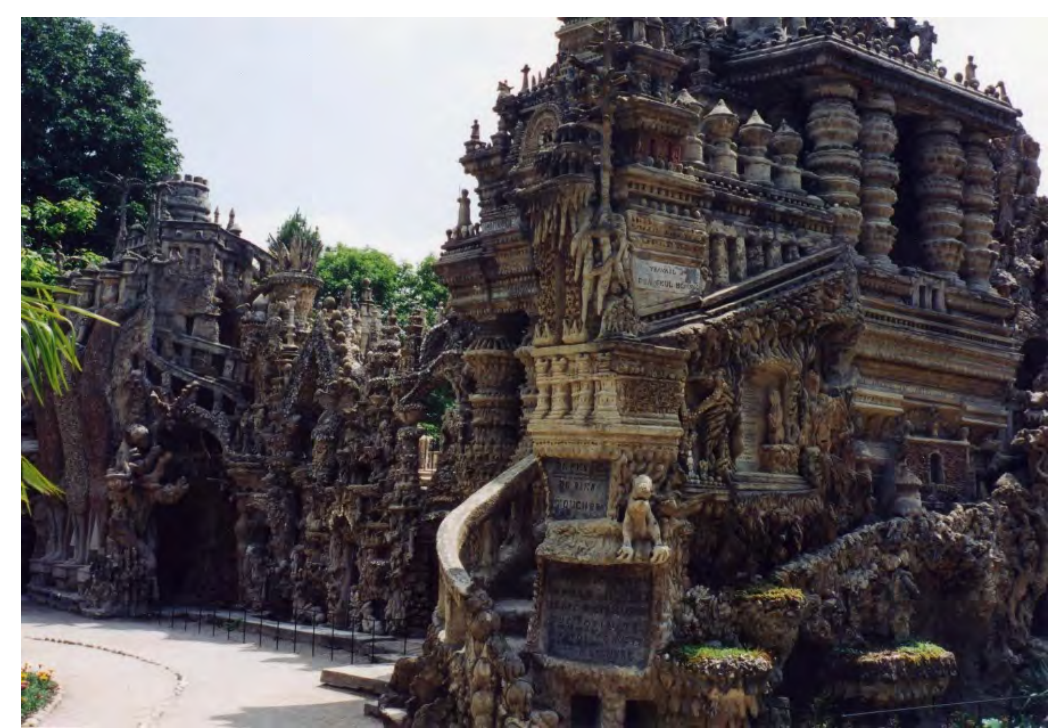

Figura 1. Ferdinand Cheval, Palácio Ideal, Hauterives, França. Fotografia do autor, 2003. 


\section{Aparição dos excluídos na história da arte}

Embora o Palais Idéal seja reconhecido como um marco dessas arquiteturas, muitos pesquisadores têm indicado a prática, tanto no século XIX, quanto nos anteriores, de arquiteturas ou esculturas enigmáticas espalhadas em regiões camponesas (Maizels, 2007), entre elas, a de Miller of Lacoste (século 19- ) ou François Michaud (1810-1890), na vila de Masgot, França. Há também relações distantes no tempo com as imagens esculpidas nos jardins de Bomarzo, na Itália (c. 1550), realizadas por hábeis oficiais sob as ordens do duque de Orsini (1523-1585), ou com a Caverna des Moisseaux, no Vale do Loire, do século XVI.

Contemporâneo ao palácio do carteiro Cheval são os rochedos esculpidos pelo abade Fouré (1839-1910), em Rothéneuf, a leste de Saint-Malo, na França. Em uma paisagem próxima à praia, o abade trabalhou por cerca de vinte e cinco anos sobre as rochas de granito, dando forma a três centenas de figuras de monstros, piratas, alegorias das mais variadas.

Atualmente, as obras artísticas de Cheval e Fouré são pontos de visitação turística - ao palácio do carteiro dirigem-se cerca de 130.000 visitantes anuais (cf. site da Associação de l'Art en Marche). Apesar da ampla malha ferroviária francesa, não há estação de trem na cidade de Hauterives. Pega-se um TGV em Paris, na gare de Lyon que, em duas horas, faz parada na gare de Valence. Para chegar ao vilarejo, podese pegar um ônibus com dias e horários variados ou locar um carro. Conforme a classificação turística, Hauterives é uma ville botanique. Muitos grupos escolares fazem visitas regulares ao lugar, além de grupos de adultos, franceses e de outros países.

Uma aleia dá acesso à entrada do palácio. Bem equipada, abriga o Office de tourisme, uma loja que vende artesanato, potes de cerâmica, bichos de pelúcia, cartões postais, outra especializada em suvenires, junto à qual está o restaurante La Galaure, também o restaurante Aux delices du Palais e uma lanchonete, chamada Le Clos. Em frente a esse espaço, uma galeria de arte foi instalada e, pouco adiante, encontrase a galeria da Associação L'Art en Marche, dedicada a artistas brutos e singulares.

O monumento do carteiro guarda a referência maior de representar o ingresso no mundo da arte de um homem comum. Delacampagne (1989), ao estudar a participação de alguns artistas das classes populares na formação da arte moderna, afirmou que Cheval representa "a irrupção dos excluídos no mundo da arte” (Delacampagne, 1989, p. 8).

O aparecimento das imagens fabulosas e fantásticas na cultura ocidental não diz respeito apenas às transformações no campo das artes, mas da manipulação de materiais com elaboração formal e simbólica no interior das classes populares. De maneira geral, a interpretação histórica mais corrente procura situar essas imagens no interior do processo de industrialização do capitalismo desenvolvido nos últimos dois séculos e pela formação de uma classe operária urbana. Mais precisamente, entre as duas últimas décadas do século XIX e a primeira metade do século XX, com as condições adversas da experiência de vida de migrantes do campo, então obrigados a morar nas cidades, submetendo-se ao tempo da fábrica.

O debate foi orientado pela afirmação acerca do caráter subversivo de criadores como Cheval. Por exemplo, Michel Ragon (1983), mesmo ao questionar os limites conferidos por Jean Dubuffet (19011985) à sua coleção de Art Brut, afirma a expressividade desses criadores, dizendo que representam a civilização rural (camponesa e bárbara) que desde o fim da Idade Média foi ocultada pela cultura erudita. Madeleine Lommel (2004), rigorosa seguidora da ortodoxia de Jean Dubuffet, dizia que a produção de objetos industrializados submeteu o trabalho artístico de mestres e artesãos, cujo desejo de formatividade plástica ressurgiria no criador bruto com finalidades diversas. Tanto Ragon (1983) como Lommel (2004) sustentam uma interpretação social da arte das pessoas de classes populares, fato que resulta em uma concepção de história marcada pelo desenvolvimento do capitalismo industrial e pela formação da classe operária, no final do século XIX, num sentido diverso do trabalho do artesão.

Coube ao filósofo Christian Delacampagne (1949-2007) ensaiar uma análise relacional da arte oficial com a história das imagens dos criadores populares, como parte da história da arte do século XX. 
Delacampagne (1989), sem vínculo direto com os historiadores de arte ou com o campo da Art Brut, sugeriu o ano de 1879 como um marco na história da "arte marginal”; o início do movimento desdobrado nas décadas seguintes. Foi o ano em que Ferdinand Cheval decidiu seguir sua empreitada de construção do que seria o Palácio Ideal, no vilarejo de Hauterives, demarcando o ingresso de um "proletário" na história da arte (Delacampagne, 1989, p. 10).

Embora não se esteja falando propriamente de um camponês migrando para a cidade, o exemplo de Cheval deixa patente a transferência de práticas estéticas das comunidades agrárias para o ambiente urbano, acrescida do individualismo moderno e de uma iconografia estranha ao artesanato camponês. Ao realizar seu estudo com o recurso da história cultural, esse filósofo verificou que os artistas populares autodidatas revelaram-se como fontes preciosas da arte moderna, ao mesmo tempo em que suas produções se tornavam, elas mesmas, obras de arte reconhecidas pela crítica.

\section{Arte popular}

A circulação dessas imagens fabulosas permite vislumbrar o contexto da problemática acima anunciada. Como dito anteriormente, trata-se do processo de industrialização do capitalismo e da formação da classe operária urbana, a partir da segunda metade do século XIX europeu. Intelectuais dedicados à formação do operariado e suas produções culturais, embora em pequeno número, interessaram-se por essas manifestações, como Michel Ragon (1924- ), localizando, ali, uma continuidade da civilização rural medieval, ocultada pela cultura erudita, no processo econômico conduzido pelo capital.

Desde o século XIX, o interesse pelas manifestações populares foi permeado pelo significado revolucionário e anticapitalista. Intelectuais franceses, pertinentes ao realismo, estão entre seus primeiros arautos, tais como: Gustav Courbet (1819-1877), no campo da pintura; Max Buchon (18181869), recuperando escritos em Besançon; Alexis Dupont (1796 - 1874 , com canções populares; e, principalmente, Jules François Félix Husson (1821-1889), cognominado Champfleury, em sua história da imaginária popular de 1869. Pouco depois, Alfred Jarry (1873-1907) e Remy de Gourmond (18581915) contribuíram para o pensamento e a arte modernos através da revista L'Ymagier (1894), na qual apareciam imagens populares de Épinal e pinturas do aduaneiro Henri Rousseau (1844-1910).

Por representarem a sobrevivência de práticas anteriores ao desenvolvimento do capitalismo industrial, essas imagens também se tornaram objeto de interesse de intelectuais conservadores, os quais, aproveitando-se de todo um conjunto de identificação e catalogação anterior, conferiram um significado muito específico para aqueles criadores de origem popular. Desde Herder (1744-1803) e os irmãos Grimm (Jacob 1785-1863; Wilheim 1786-1859), possibilitava-se o reconhecimento referindo-se ao "povo".

O termo folk-lore aparece nesse contexto, em 1846, de um escrito de William John Thoms (1803-1885), na revista Atheneaum de Londres. Desde então, surgiu uma série de grupos na Inglaterra dedicados ao tema. Circunscreviam saberes populares em risco de desaparecer, sobretudo oriundos das tradições orais, por vezes, registros literários, contos, superstições. Ao que se seguiu o interesse por fazeres, culinária, hábitos, indumentária, também alguns objetos, móveis e utensílios. Convém lembrar que as imagens impressas ou pintadas não foram, no primeiro momento, objeto de interesse.

Alguns autores franceses poderiam ser relembrados aqui, tal como Paul Sébillot (1843-1918) que, em torno de 1860, defendia os "temas provincianos", "rústicos”, o “imaginário bretão”. No Congresso Internacional de Tradições Populares (Paris, 1889), propunha-se a criação de um museu, a ser instalado nas dependências do Trocadero. Além do valor documental, também o valor artístico foi defendido por alguns participantes, como se nota na conferência de Émile Blémont (1839-1927), autor do livro intitulado Estética da Tradição publicado em Paris, em 1890.

No Brasil, os estudos folclóricos foram muito baseados em autores alemães e italianos. Os intelectuais que se destacaram foram Sylvio Romero (1851-1914), atuando em Sergipe e Pernambuco; Celso 
Magalhães (1849-1879), no Maranhão; Carlos Kozeritz (1830-1890), no Rio Grande do Sul. O primeiro curso de folclore neste país foi ministrado por João Ribeiro (1860-1934), em 1913, quando se falava em “demologia”, que significava saber popular, referindo uma área de estudos que interessou aos primeiros psicólogos sociais do Brasil, como Artur Ramos (1903-1949).

No espaço europeu, de modo esquemático, duas posições opostas dividiram o campo de significados das imagens populares. De um lado, considerava-se as imagens populares em sentido revolucionário, como se disse, anticapitalista, de outro, estariam vinculadas ao pensamento conservador.

Recupero algumas considerações formuladas por Renato Ortiz (1985), as quais nos permitem compreender melhor esse processo de significação. A nomeação proposta pelos ingleses tornou-se hegemônica em todo o mundo, com algumas variações, cuja origem remete à contraposição entre tradição e progresso, ao primórdio da globalização: “A história do povo, tal como ela é apresentada por uma corrente marxista e socialista, se faz a partir de baixo, enquanto que a perspectiva dos folcloristas corresponderia a uma historiografia a partir do alto." Porém, continua o autor: "Os folcloristas introduzem uma escala de apreensão dos fenômenos sociais distinta daquela proposta pela história do Estado e da civilização. [...] Apesar de toda a crítica que possa ser feita, eles constituem quase que a única fonte de referência que permita uma reconstrução do passado.” (Ortiz, 1985, p. 17).

Em suma, a designação de arte popular é ambígua desde sua origem; refere tanto "proletários rebeldes" quanto "camponeses tradicionais". O reconhecimento dos objetos criados entre os membros das classes populares guarda essas oscilações, porque sua história foi escrita em duas perspectivas antagônicas: na forma negativa, pela constituição do campo artístico, a definir uma arte verdadeira e uma arte menor; e na forma positiva, conforme os folcloristas. Entre as duas posições, combinaram-se posições de intelectuais críticos, que pleiteiam o caráter revolucionário da criação popular em relação à cultura dominante, e intelectuais conservadores, para os quais aquelas imagens eram registros de práticas remanescentes de tradições rurais. Particularmente, no Brasil, a tensão foi estabelecida entre a questão das lutas sociais e a ilusão acerca de uma cordialidade campestre do ser brasileiro.

Em ambos os casos, opera-se a uma distinção, pois se perde a gênese da experiência estética das classes populares e da origem das imagens fantásticas. Notadamente, na história do carteiro Cheval, encontrase uma personagem singular que não era nem camponês, nem operário.

\section{Construtores, arquiteturas fantásticas e habitantes paisagistas}

\subsection{Designações}

As décadas de 1960 e 1970 foram frutíferas para a visualização das imagens de criadores populares, capturadas em diversos lugares em arquiteturas equivalentes à de Cheval. As designações para essas construções foram tão variadas quanto as formas apresentadas. Na França, Gilles Ehrmann (1962), em um livro cuja introdução fora escrita por André Breton, referia-se aos "inspirados e suas moradias", enquanto nos Estados Unidos Gregg Blasdel (1968) falava em “artistas de raiz”. Na década de 1970, encontram-se nomes, tais como os "habitantes paisagistas" ou os "jardins imaginários", na importante visão de Bernard Lassus (1975), e "os inspirados de beira de estrada”, de Jacques Verroust (1978). Vertidos do inglês, são também notáveis termos como "ambientes visionários” e "arquiteturas fantásticas”.

Desde a publicação do livro de Ehrmann (1962), considera-se uma mudança na percepção de tais obras, bem como pelos escritos de Bernard Lassus (1929- ), um agente importante na preservação dessas criações efêmeras (Maizels, 2007). Uma série de fotógrafos passou a registrar esses lugares, a exemplo de Claude e Clovis Prévost (Clóvis 1940- ; Claude séc. 20- ), cujo livro seria intitulado "os construtores do imaginário". O então jovem pintor nova-iorquino Gregg Blasdel, publicou na Art in America n. 56 (1968) um artigo intitulado "The grass-roots artist”. Ali apresentou registros fotográficos de obras de arquitetura espontânea que são, no subtítulo, comparáveis com a do carteiro Cheval e de Simon Rodia 
(1879-1965). Claude Arz (1995) retomou o trabalho de catalogação e registro de autores franceses da década de 1970, para mostrar o crescente interesse por essas arquiteturas.

No Brasil, a orientação antropológica de Lélia Frota (1978) ampliou o círculo restrito das obras artísticas, considerando em seu ensaio a arquitetura popular desenvolvida de modo pessoal, como a Casa dos Cacos de Carlos Luiz de Almeida (1910-1989) no bairro Bernardo Monteiro (Belo Horizonte, MG): "um edifício de embrechados: inteiramente revestido de fragmentos de louça, formando figuras geométricas e antropomorfas, com esculturas de animais tratados pelo mesmo processo no jardim" (Frota, 1978, p. 10).

Naquele momento, era conhecida a filmagem de Carlos Augusto Calil (1951- ) revelando o Simitério do Adão e Eva, obra de Jakim Volanuk (1900-1990) nos fundos de sua casa no bairro da Mooca (São Paulo, SP), assim como a Casa da Flor, de Gabriel Joaquim dos Santos (1892-1985), realizada com aplicações de cacos e conchas sobre uma tapera em Baixo Grande (RJ). O livro coordenado por Fernando Freitas Fuão (1999), dedicado a Arquiteturas fantásticas, apresenta uma mostra importante dessas imagens. O “mundo ovo” de Eli Heil (1929- ) (Florianópolis, SC) tem figurado nessas histórias. Mais recentemente, ganhou notoriedade a casa de Estevão da Conceição (1957- ), designado o "Gaudi de Paraisópolis” (São Paulo, SP). Há relatos também do castelo de João Capão (1935-2016), em Guaranhuns (PE), do Jardim do Nego, Geraldo Simplício (1943- ), em Nova Friburgo (RJ), entre outros.

Para se manter o foco nas questões inicialmente assinaladas, dois exemplos serão citados a seguir: a Maison Picassiette, na França, e a Casa da Flor, no Brasil.

\subsection{Maison Picassiette}

A primeira, foi comprada pela municipalidade de Chartres e elevada a monumento histórico, em 1981, tornando-se um museu inscrito nos guias turísticos locais. Seu autor, Raymond Isidore (1900-1964), dito Picassiette, nasceu e viveu naquela cidade francesa entre 1904 e 1964. Com os proventos do trabalho em uma usina de fundição, comprou um terreno e construiu sua modesta residência. Problemas de saúde obrigaram-no a deixar o emprego em 1937, período em que se dedicou a atividades temporárias, tais como a recuperação de pedaços de mármore, entre outros materiais, para servirem de ladrilhos. Originase, aí, a coleta de pedaços de faiança, louças, cerâmicas, cacos de vidro com os quais decorava a pequena casa que ele próprio construíra com sua esposa.

Com o tempo, todos os espaços da casa foram ganhando imagens em mosaicos. O piso da entrada e do corredor, as paredes da casa e os muros ao redor, ao final, também os móveis começaram a receber essa decoração; hoje, pode-se contemplar o fogão, as cadeiras, a cristaleira, a cama do casal, tudo revestido de cacos. As imagens formadas a partir da composição desses objetos inspiraram-se em cartões postais, jornais ilustrados e calendários (Maizels, 2007).

A casinha de três cômodos situa-se no centro do terreno, onde outras construções na mesma proporção foram edificadas. A vontade de enriquecimento do meio onde vivia fez com que Isidore planejasse e executasse em todos os cantos sua obra. Na entrada do terreno, cercado por uma cerca feita em flores de cimento, o piso apresenta-se inteiramente decorado com mosaicos, em formas circulares. No muro à esquerda, liso e sem flores, três imagens foram pintadas em afrescos: a do centro é a catedral de Chartres, as outras são dois castelos. Passando pelo corredor lateral, o olhar percorre toda a parede da casa. Uma cena de mulher com pássaros, a paisagem da vila de Chartres, animais, à direita, uma maquete de castelo serve de vaso. Entra-se então em um espaço que permite acesso à capela, à esquerda, e a uma saleta, à direita. Nesta última, há um penduricalho feito com bicos de bules. Estes ambientes são iluminados por clarabóias de vidro no teto. A capela está totalmente preenchida de mosaicos. Uma cruz em cimento fixada na parede marca o local do altar. Na parede oposta, uma cena sagrada. Nas paredes laterais, personagens bíblicos estão registrados. 




Figura 2. Raymond Isidore, Maison Picassiette, Chartres, França. Fotografia do autor, 2003.

Prosseguindo pelo corredor, atinge-se um ambiente aberto, marcado por uma peça no centro, à maneira de uma mesa altar, e um trono à frente. Sobre essa mesa foi depositada uma maquete em cimento da catedral de Chartres; aos pés da mesa, estão gravadas as duas mãos do artista. Ali está uma escultura do casal Isidore. Todas as paredes estão recobertas de mosaicos representando fachadas de igrejas diversas.

O jardim, nos fundos da residência, dispõe várias esculturas ao visitante, das quais três são memoráveis: a escultura de sua esposa em tamanho natural; seu próprio busto; a torre Eiffel. Ao longo dos caminhos, pequenos nichos, curiosamente decorados com restos de esculturas, faces, cães. Contornando o jardim, que envolve os fundos da casa, encontra-se uma gruta, dentro da qual está um pináculo onde estão registradas as seguintes palavras do alto para baixo: “Dieu, Jesus, Marie, Joseph, (?), ici repose l'esprit”.

Estes mosaicos são realizados com cacos diversos; além dos pedaços de ladrilhos, há muitas peças de vidros verdes de garrafas, fragmentos de pratos, xícaras; em alguns detalhes vê-se restos de peças de louça, cabecinhas de estatuetas, pegadores de bules. Não são muitas as conchas, mas há algumas. Submissas aos mosaicos, estão pinturas em afresco com cenas da vida cotidiana, representação de pessoas e uma infinidade de fachadas de igrejas.

A preocupação com a simetria é marcante em todo o trabalho; a parede que apresenta os vasos, colocaos exatamente um de cada lado da janela fronteiriça. No detalhe do menino, ladeado de duas flores na porta da capela, percebe-se essa preocupação. As flores são frequentes em toda a casa, tanto na representação em mosaicos, quanto em potencial nos vários vasos. De modo mais solene, há rosáceas pelo chão e paredes. Elas remetem à arquitetura religiosa, tema central das imagens. A personagem principal é uma mulher, provavelmente sua esposa. Há uma escultura em cimento pintado em que o casal está abraçado. Além do busto em sua própria homenagem, existe um autorretrato em afresco no cômodo que antecede o jardim. Raymond era um homem magro, relativamente baixo, autorrepresentado com seu bigode negro e sempre com um chapéu. O painel da mulher com pássaros, ao lado da porta da entrada, chama a atenção, bem como uma cena de uma mulher com crianças e animais num quintal de casa rural. Notase, ainda, muitos barcos em cenas diversas. São vários os animais, alguns exóticos; mais visíveis são os pássaros, mas há cães, cisnes, gamos e girafas. Uma grande abelha está sobre uma das janelas da lateral; uma borboleta sobre a outra.

A principal paisagem, talvez, seja aquela realizada entre as duas janelas laterais, na qual se vê o outeiro da vila de Chartres esculpido em cimento. A igreja do alto domina a cena, seguida abaixo pelas casinhas. Desse tema maior e mais recorrente, desdobra-se a incrível quantidade de fachadas de igrejas, cenas importantes para o imaginário religioso, mas também, do mundo turístico da França. O afresco, realizado na cozinha e sala de jantar, apresenta o Monte Saint-Michel, um marco dentre as imagens francesas. Para Lommel (2004), ao trabalhar sob a sombra da Catedral, ressalta-se a humildade do construtor. 


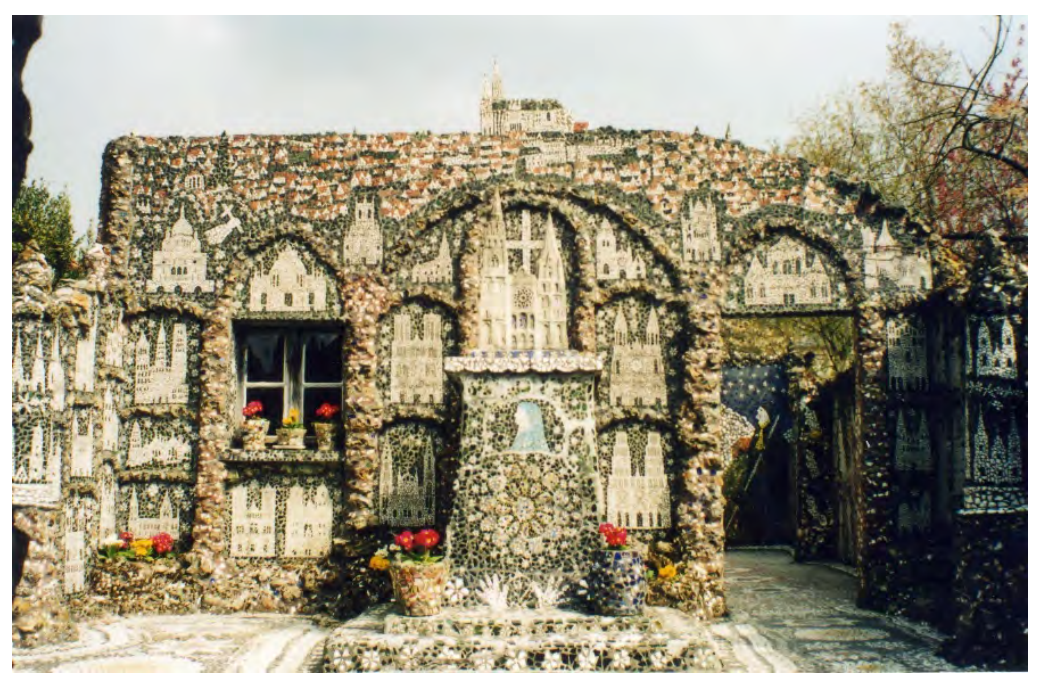

Figura 3. Raymond Isidore, Maison Picassiette, Chartres, França. Fotografia do autor, 2003.

\subsection{A Casa da Flor}

O exemplar brasileiro foi construído por Gabriel Joaquim dos Santos (1892-1985), entre 1912 e 1923, em um terreno pertencente à família, atualmente no município de São Pedro da Aldeia, estado do Rio de Janeiro. Gabriel nascera filho de índia com ex-escravo, não frequentou escola e desempenhou trabalhos diversos, particularmente nas salinas da Região dos Lagos (RJ) (Zaluar, 1997). Ele estava quase cego quando foi entrevistado e fotografado em 1981, por ocasião dos preparativos da exposição de Arte Incomum, módulo inscrito na Bienal Internacional de São Paulo daquele ano. Os depoimentos colhidos, então, por José Augusto Varella (séc. 20- ) e José Roberto Cecato (1953- ) fornecem pistas importantes sobre o que encontraram: "Em São Paulo, no Rio, tem castelo, tudo bonito, é a força da riqueza, mas casa de caco não tem”. (como citado em XVI Bienal de São Paulo, 1981. p. 91)

A implantação, instalada em elevação do terreno, é percebida com certa delicadeza, uma forma levemente tortuosa do telhado de barro, o qual parece harmonizar com as curvas do terreno e com a esparsa vegetação local. Muito rapidamente pode-se circundar a construção, vê-la de cima, devido à posição da encosta, ter a atenção voltada para o imbricado de pedras e materiais na conformação de muretas e arrimos. Na entrada principal, ao fim de uma escadaria de pedra ladeada por vasos encrustados, depara-se com a inscrição do autor: "Casa da Flôr, 1923". O escrito foi feito com letras em relevo, enquanto a escultura da flor emerge de cacos e barro moldado. Ao lado, uma grande flor feita em mosaico de cacos de cerâmica. Trata-se de uma pequena construção de três cômodos, edificada em pau-a-pique, pouco iluminada e de mobiliário exíguo, embora repleta de decoração modesta. Esses ornamentos estão em profusão pelas paredes, entre azulejos, cacos de cerâmica, búzios; compõem o espaço os coquetéis de lâmpadas dependurados no forro de maneira. 


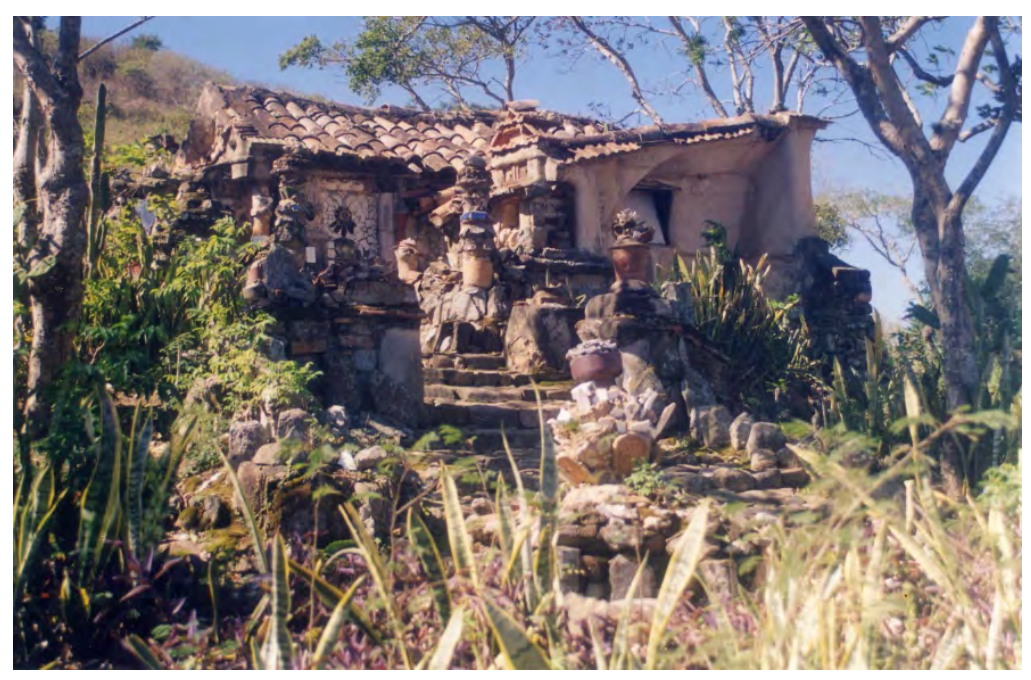

Figura 4. Gabriel dos Santos, Casa da Flor, São Pedro da Aldeia, RJ. Fotografia do autor, 2012.

Em 1978, Leonardo Fróes (1941- ) assinou o livreto como um dos primeiros registros da casa. As palavras do autor, em sua forma poética, informam sobre o valor estético da construção:

O espaço coberto é quase nada - parece uma casinha de anões. Os três cubículos interligados, em plena tarde, com o sol bem firme no céu puro, recebem apenas umas gotas de luz, seja por duas portas de altura irrisória ou por frestas eventuais entre as grandes telhas escuras. Desprovido de arestas, curtido pelo tempo, o telhado na verdade parece um toldo de barro, é feito de movimentos e ondas como o corpo de um bicho. (XVI Bienal de São Paulo,1981, p. 91)

Conta-nos a publicação que a história da Casa da Flor começou com um sonho de criança, em uma referência explícita ao domínio do imaginário, mas não apenas isso, há uma constante referência ao trabalho manual. Gabriel quase não utilizou ferramentas, aplicando a força das mãos. Daí o comentário de Fróes: "O caráter gestual desabrido percorre, assim, toda a obra desse pedreiro-escultor. Em seus volumes modelados com verdadeiros afagos é possível notar, então, as pulsações de uma vida; a casa tem um corpo...” (como citado em XVI Bienal de São Paulo, 1981, p. 93).

O reconhecimento da arquitetura de Gabriel dos Santos contém algumas indicações importantes para este artigo. Na matéria divulgada pelo portal do Instituto do Patrimônio Histórico Nacional, em setembro de 2016, por ocasião da inscrição da Casa da Flor no Livro do Tombo de Belas Artes, mencionou-se sua "singularidade" e "unicidade”.

Em seu parecer, o relator e conselheiro Leonardo Castriota, comparou a Casa da Flor a outras obras internacionais também reconhecidas como patrimônio cultural em seus países, como a Watts Towers, em Los Angeles (Estados Unidos) - criadas por Sabato Rodia (1879-1965), um imigrante italiano trabalhador da construção civil - e o Palais Idéal du Facteur Cheval, em Hauterives (França) - construído por Ferdinand Cheval (1836-1924), um carteiro francês

$[\ldots]$

De acordo com o parecer do Iphan, entre as justificativas para o tombamento da Casa da Flor está o ineditismo criativo, que instiga ao debate sobre os processos de produção cultural. O documento destaca que "a Casa da Flor condensa esse esforço de ordenar a desordem, a fragmentação e as oposições, de acordo com um conhecimento do valor das coisas e não da sua utilidade meramente funcional.” (Iphan, 2016) 


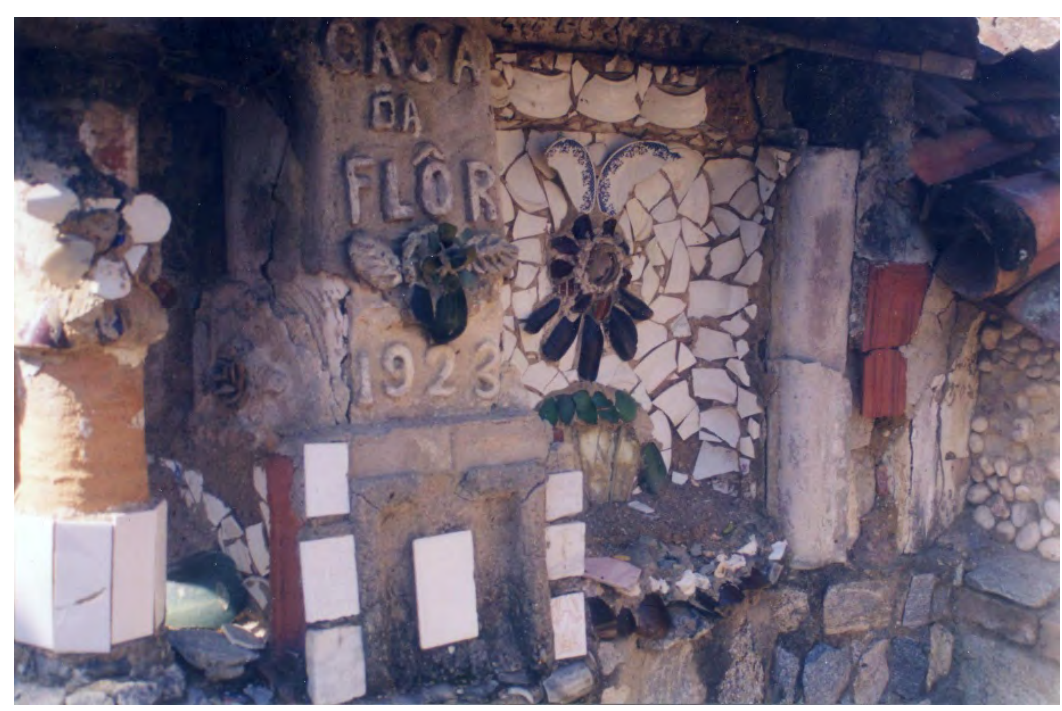

Figura 5. Gabriel dos Santos, Casa da Flor, São Pedro da Aldeia, RJ. Fotografia do autor, 2012.

\section{Arte, imaginário e experiência estética}

O problema central deste texto reserva um domínio sociológico, em sua origem conceitual acerca da existência de um campo social, com centro e periferia, ou ainda da disputa entre grupos de profissionais de artes por posições privilegiadas face ao poder no interior desse campo. As particularidades dos criadores citados exigem um posicionamento frente ao campo artístico e ao imaginário brasileiro. De modo mais amplo, o exame dessas arquiteturas fantásticas ou fabulosas referem três termos fundamentais que fornecem indicativos para compreender os processos implicados nas imagens populares: arte, imaginação e experiência estética. Evidentemente, para cada um destes termos há significados complexos que não serão explorados aqui; o objetivo será tão somente indicar algumas vias para o conhecimento psicossocial a partir do objeto deste estudo.

A questão da arte aparece desde o início, tanto pela nomeação dirigida a tais objetos quanto pelo valor que adquirem. Observamos no início deste artigo uma tensão provocada pela sociologia de Bourdieu e os intelectuais ligados à arte bruta, assim como em relação aos proponentes do folclore, nas fronteiras de noções como arte bruta e arte incomum, ingênuos e singulares.

Jean Dubuffet (1999, p. 106) defendeu a existência de uma Art Brut em uma posição anti-cultural da história europeia. Os autores da arte bruta são pessoas que por algum motivo escaparam aos condicionamentos culturais, ao conformismo social, estranhas aos meios intelectuais, sem formação artística, ignorantes à tradição cultural, inadaptadas socialmente, indiferentes ao reconhecimento e à promoção comercial, cuja criação é solitária e clandestina, realizada com meios técnicos humildes, reveladoras de uma forte tensão mental, invenção sem freios, reinvenção das etapas do ato criador, totalmente livres e com pureza de expressão (Dubuffet, 1964, p. 3; Thévoz, 1980, p. 12; Peiry, 1997, ps. 93, 121 e 197). Dentro desses critérios, o próprio Dubuffet resistiu a considerar os construtores e suas arquiteturas fantásticas como integrantes do campo da arte bruta. Apesar de fundamentar-se em critérios muito distintos, o resultado fora o mesmo da recusa assinalada por Bourdieu; o não reconhecimento dessas construções como objeto de conhecimento social.

Mostrou-se que o reconhecimento desses criadores está demarcado por contradições, entre elas, afirmações opostas de serem meras cópias de folhetins ou obras revolucionárias. Interessa para este artigo aquilo que Thévoz (1980) registrou como um dado inquestionável; a existência do objeto. Há um fenômeno a ser observado e sua constituição pode fornecer pistas importantes sobre o conhecimento sensível tal como é vivido em membros das classes populares. 
As tensões acompanham os estudos das imagens populares em todo o seu reconhecimento como "de arte”. Por exemplo, o intelectual português Ernesto de Sousa (1973) considerava a escassez de investigações mais profundas desse fenômeno e o fato de ignorarem o fator estético. Esses estudos incorriam em equívocos ao atravessarem o campo da arte, pois admitiam uma concepção estética com base na cultura erudita oitocentista, ao nomearem o objeto de "arte”, assim como a imprecisão acerca do significado da palavra "popular". Outro ponto crítico está na distinção entre arte e artesanato, muitas vezes remetendo à oposição entre urbano e rural. Para situar sua proposta nesse campo impreciso, Ernesto de Souza (1973) designou um “complexo estético ingênuo” em contraposição à “imitação e anonimato mais pobre”: "As nossas observações levaram-nos à conclusão de que é mais fácil encontrar uma atividade desse [último] tipo na cidade do que no ambiente rural.” (Souza, 1973, p. 63). Nota, então, duas categorias, uma dedicada à atividade artesanal com liberdade criadora, outra de "verdadeiros outsiders", "artistas ingênuos” surgidos em grande parte nas cidades, a exemplo do Douanier Rousseau e do Facteur Cheval.

O termo “ingênuo” aplicado à arte, por sua vez, abre outra problemática, sobretudo porque se caracteriza atualmente mais por uma determinada técnica (pintura de temas campestres em cores primárias) que propriamente pela origem popular do artista. Convém apenas lembrar que esse termo aparece na sociologia de Howard Becker (1983) para designar um tipo de artista. O autor propôs a configuração do "mundo da arte" não apenas baseado em um único tipo social chamado "artista”, mas "tipos" distintos organizados em quatro categorias, divididas pelo maior ou menor grau de conformidade diante dos comportamentos dominantes: 1) profissional integrado; 2) mavericks; 3) naïfs; 4) populares.

Os artistas naïfs ou ingênuos são aqueles que não conhecem os membros do mundo artístico e não possuem formação, sabem pouco sobre seu modo de expressão, suas histórias ou convenções. Os artistas populares, na definição de Becker (1983), estariam situados onde não existe nenhuma comunidade artística profissional, por isso são distintos dos naïfs, sua obra não é compreendida como de arte, mesmo se pessoas externas à comunidade encontrem ali "mérito artístico".

Becker (1983) posicionava entre os artistas ingênuos nomes como o de Simon Rodia, construtor das Watts Towers, e o carteiro Cheval. A formulação do sociólogo de Chicago precisou dois pontos essenciais deste problema: o da solidão em que vivem os autores dessas obras e a impossibilidade da linguagem para explicá-las: "Incapazes de exprimir aquilo que fazem em termos convencionais, os artistas naïfs trabalham sós.” (Becker, 1983, p. 411).

Como mencionado acima, a extensão desse problema vai muito além da terminologia e refere-se ao conhecimento crítico da arte em sociologia, história, psicologia social, entre outras disciplinas. Embora tomado como uma evidência por muitos autores, a noção de "arte” está histórica e socialmente situada, fazendo com que as questões apresentadas diante das imagens populares assumam uma dimensão mais ampla, não apenas do reconhecimento de determinados objetos como de arte, mas da própria hierarquia social dos objetos. Recentemente, sociólogos franceses como Roberta Shapiro (2007, p. 135) têm conduzido essa discussão por meio do conceito de "artificação": "a transformação da não-arte em arte". Esta socióloga busca descrever processos sociais nos quais objetos cotidianos convertem-se em arte, não apenas a partir de definições de instituições e disciplinas consagradas, mas como um fenômeno que emerge em situações sociais específicas, como é exemplar o caso do hip hop.

Pierre Bourdieu elaborara sua reflexão do campo social da arte por intermédio da formação do habitus de classe, de modo a examinar as posições e determinações na percepção da arte. Por essa via, não há escapatória à conclusão de ser a "arte bruta”, “ingênua” ou "incomum”, uma invenção do olhar cultivado do intelectual. Por outro lado, percorrendo os diversos exemplares citados neste artigo, pode-se notar que o ponto central da crítica bourdiana pode ser lido em outra perspectiva. O uso de revistas de época, cartões postais, ou outras fontes iconográficas popularizadas, não retira por si só o valor dessas figurações, pois não se poderia considerar essa prática como uma submissão à ideologia. Apresentamse, sobretudo, como elementos de um imaginário complexo em constante transformação. Nessa linha, não se quer afirmar o contrário. Ou seja, o caráter revolucionário dessas manifestações, como fizeram 
Delacampagne (1989) e Lommel (2004). Trata-se de reencontrar o fenômeno dessa produção imagética como forma de conhecimento social.

Decorre daí os dois últimos tópicos a serem citados neste artigo. As manifestações artísticas populares observadas neste estudo articulam a atividade imaginativa a uma experiência sensória específica, das quais surgem imagens novas em uma dimensão material de confecção.

Há paralelos notáveis entre as descrições de muitas construções similares. Gabriel dos Santos dizia: “A escada de pedra é feita de pensamento"; "Eu sonho pra fazer uma flor de caco de garrafa, eu vou fazendo". A mesma referência à atividade onírica aparecia em Cheval e outros. Allen Weiss (1992, p. 294) afirmou: “a profundidade incompreensível do simbólico é uma função da circunstancialidade, do local, da situação histórica”. Para esse autor, a contingência é absorvida e expressa pelo estereotipado, em símbolos culturais reinterpretados. Isso é demonstrado pelo exame da produção de artistas brutos tais como Adolf Wölfli (1864-1930), Carlo Zinelli (1916-1974) e Jeanne Tripier (1869-1944). Assim, o fechamento simbólico dessas criações sobre si mesmas não lhes tira seu significado histórico, sobretudo porque é na temporalidade de um ser social que elas se manifestam.

Para Weiss (1992), o ponto onde o simbólico ingressa na história confere o nexo em que o processo de particularização e de socialização do indivíduo relaciona-se com os eventos contemporâneos:

\footnotetext{
O corpo é o lugar dessa contingência - onde o magma do imaginário e as exigências da história manifestam sua conexão em sonhos, símbolos e atos. Embora haja sempre um significado nesse ponto inatingível, esse significado, esse nexo original, pode ser qualquer coisa; isso permanece ainda desconhecido, não porque foi reprimido, mas, porque é inelutavelmente real. [...] Talvez o único caminho para nós atingirmos verdadeiramente a trama simbólica no âmago dessas obras não seja através da nossa crítica, mas, sobretudo, nos sonhos e pesadelos que elas produzem. (Weiss, 1992, p. 294)
}

O fato de Raymond Isidore ou Ferdinand Cheval copiarem cartões postais ou folhetins não deveria ser um impedimento acerca do conhecimento ali emergente, mas o meio para sua interpretação nos termos que lhe são próprios. Lommel (2004, p. 171) havia observado a importância das mãos desses trabalhadores. Há uma relação com a manipulação de massas notável nos criadores que colecionou, dentre os quais estavam pedreiros e padeiros. Se por um lado, a pertinência da atividade imaginativa na tarefa desses construtores é inquestionável, por outro, ela está imbricada com um fazer próprio, das mãos, manipulando um ambiente específico. A coleta de materiais variados e a transformação do mundo vivido através do trabalho manual resultam na criação de formas novas e imagens fantásticas.

A atividade da imaginação concretiza-se através das mãos em forma de bricolagem. As referências a Estevão, o "Gaudi de Paraisópolis", as imagens da natureza, em relevos orgânicos, remetem tanto à observação da natureza, quanto ao trato manual do ladrilho, seixos e embrechados. Michel Thévoz (1980) havia mencionado o valor da bricolagem. O bricoleur reúne fragmentos de objetos para ter a ideia do que confeccionar a posteriori. Ou seja, há uma "iniciativa do material”, uma lógica e uma contingência não previstas no pensamento criativo: "o diálogo com o material é ali determinante" (Thévoz, 1980, p. 70). Essa tarefa é realizada em um nível da experiência distinto da racionalidade do conhecimento científico. O trabalho plástico processa-se através de acidentes de execução, da significação surgida a partir das próprias formas dos fragmentos. A ambiguidade é determinante, a solicitação do material não bloqueia a atividade da imaginação, pois estabelecem um jogo de mão-dupla. Esse jogo é próprio da experiência estética e permite a aproximação de um nível fundamental do conhecimento.

A etimologia da palavra estética tem sido importante para a conceituação dos processos apresentados neste artigo. Alexander Gottlieb Baumgarten (1714-1762) forneceu, em 1750, a definição de estética como o a ciência do conhecimento sensório. Porém, devido à vinculação da categoria do belo, foi aproximado do debate das artes durante o século XIX. Não obstante, tratava-se de uma ciência que exploraria a experiência sensória; aisthesis na origem grega, dizia respeito à "percepção pelos sentidos" (Berleant, 2010, p. 26). Nesta acepção, considera-se a "estética da vida cotidiana” distinta, mas não menor que a estética circunscrita ao campo das artes. Nas palavras de Arnold Berleant (2010, p. 27): 
"Reconhecendo que a estética começa e termina na experiência sensória, nós podemos ao menos a princípio considerar esteticamente qualquer objeto e qualquer experiência que pode ser sentida”

Esse filósofo fornece, então, uma contribuição decisiva: “Falando de estética, nós precisamos, portanto, ir além da beleza, precisamos ir além dos objetos que são agradáveis, e focar nossa experiência de tais objetos, pode-se tocá-los apenas através da experiência” (Berleant, 2010, p. 29). Deste ponto de vista, a estética não é uma verdade universal e imutável, mas uma forma de conhecimento que possibilita pensar a vida humana no que diz respeito à capacidade da experiência perceptiva. A percepção incorpora, além dos sentidos, as características psicológicas e culturais. A experiência estética não é pura, jamais é simples sensação; ela não é apenas mediada pela cultura, mas é inerentemente cultural (Berleant, 2010, p. 45). O campo da experiência estética não abandona sua dimensão artística, mas expande-se pelas atividades culturais ao meio ambiente; da beleza natural ao ambiente construído da vida cotidiana.

Está colocada uma distinção entre o significado na acepção cognitiva e aquilo que se poderia chamar de experiência do significado: significado cognitivo e significado experiencial. A percepção é ocupada pelo significado e envolve a consciência do significado.

\begin{abstract}
Significado experienciado é complexo e indistinto. Ele abriga tons de sentimentos, postura corporal, ressonâncias mnemônicas, associações e intimações as quais não podem ser articuladas senão por seu próprio modo, pelas artes, particularmente, talvez, literatura e música. Falando de estética, nós precisamos, portanto, ir além da beleza, precisamos ir além dos objetos que são agradáveis, e focar nossa experiência de tais objetos, pode-se tocá-los apenas através da experiência.” (Berleant, 2010, p. 29)
\end{abstract}

Nesta concepção, a experiência estética possui dois aspectos principais: o sensório, primário; e a experiência dos significados. Tema compreensível por meio da arte, na experiência de objetos ou situações, presentes ou imaginários, mas também na percepção qualitativa de processos naturais e sociais. Considera-se experiência primária aquela mais direta, imediata, ou forma pura de apreensão: “Toda experiência é estética por definição porque experienciar é equivalente a aesthesis.” (Mandoki, 2007, p. 35 como citado em Berleant, 2010, p. 35) Tal experiência pode ser positiva, negativa, ou apenas informativa. A percepção comporta a experiência sensória, as mediações formadas pelas instâncias psicológicas e culturais, os padrões de apreensão e as múltiplas forças provenientes do mundo (Berleant, 2010, p. 35).

Muitas vezes a estética tem sido referida como pré-cognitiva ou não-cognitiva. Ambas concepções resultam da história do conhecimento nos últimos dois séculos, durante a qual pensamento e pragmática estão separados. De modo esquemático, o autor propõe compreender a percepção estética como fonte do processo de conhecimento ao que designou "argumento estético em epistemologia” (Berleant, 2010, p. $54)$.

Esse procedimento não se reduz à elaboração teórica, pois está situado na experiência da vida, junto ao qual o processo estético é entendido como fundante da significação social e política e se organiza a partir de dois requisitos meta-cognitivos: (1) identificar, descrever, explicar tipos e variedades de construções cognitivas emergentes no tempo e no espaço, por meio da história, da sociológica, entre outras disciplinas; (2) usar a percepção e a experiência estética para considerá-los criticamente, conforme o argumento estético (Berleant, 2010, p. 5).

\title{
6. Conclusão
}

Neste texto, foram deixadas de lado dimensões distintas da experiência estética de gente comum, seja da organização sensória da vida cotidiana, seja contemplação do mundo, para restringir a compreensão das imagens provenientes, sobretudo, no debate concernente ás camadas populares, pobres e sem instrução formal para as artes, em referência às arquiteturas fantásticas. No processo histórico contemporâneo, emerge um campo mais complexo de produções, tal como registrou Michel Colardelle (1999), ex-diretor do Museu de Artes e Tradições Populares da França, referindo as novas experiências populares distintas do conjunto anônimo de práticas coletivas. 
Madeleine Lommel (2004) trouxe a essa discussão uma dimensão histórica a ser considerada. Originalmente baseada na ortodoxia dubuffettiana, ela mesma colecionadora do que se tornou a Coleção l'Aracine, compreendia a arte bruta e todas essas manifestações singulares surgidas das mãos de pessoas comuns, sem contato com o campo artístico, incluindo o carteiro Cheval, como o ressurgimento de um impulso formativo. Tal impulso, antes desviado para práticas coletivas populares, de mestres, oficiais e artesãos, irrompe em pessoas fora do campo artístico, por vezes de modo violento, como num tipo de recalque.

Concentrando o exercício de reflexão no processo histórico, a compreensão estética contemporânea resulta de uma tensão em relação ao estatuto da experiência dos sentidos frente ao discurso de uma arte desinteressada, proveniente do campo artístico, como notou Bourdieu (1979), em noções como hierarquização e distinção. Não obstante, será necessário adotar uma postura compreensiva que solicita o reconhecimento dessa experiência sensória em sua legitimidade, como fundamento da vida social e política, na proposição mais recente de Arnold Berleant (2010).

Diante da complexidade daquelas construções, propôs-se uma distinção entre o significado cognitivo e o significado experiencial, por meio da qual a atividade imaginativa está imbricada com o fazer próprio das mãos, na manipulação do ambiente. As solicitações do ambiente não limitam a atividade da imaginação, uma vez que participam do jogo próprio da experiência estética como forma de conhecimento social.

No centro daquelas experiências, designando os "construtores do imaginário" ou os "habitantes paisagistas”, está em operação a transformação do mundo em imagens. Algumas imagens emergem do sonho, remetem à natureza ou à cultura, mas todas retomam a experiência vital do corpo no mundo. Quando se adentra a Casa da Flor ou o Palácio Ideal, não é possível sustentar o olhar objetivo, mas entrega-se a um outro olhar, ao olhar do outro. Esses criadores modestos obrigam o observador a uma dupla viagem - uma no espaço geográfico, outra no imaginativo; daí constituírem-se como os "viajantes do lugar”. Essa obra, em grande parte inominável, abre a sensibilidade para uma outra ordem de saber social, aquela resultante do processo de significação primária do contato do corpo com o mundo, mas não em oposição ao social, uma vez que o social lhe é inerente.

\section{Referências}

XVI Bienal de São Paulo (1981). Arte Incomum [Catálogo]. (pp. 93-95). São Paulo: Bienal de São Paulo.

Barata, M. (1950). Conceito e metodologia das artes populares. Rio de Janeiro: MEC.

Becker, H. (1983). Mondes de l’Art et types sociaux. Sociologie du Travail, 4, 404-417.

Berleant, A. (2010) Sensibility and sense: the aesthetic transformation of the human world. Exeter (UK)/Charlottesville (US): Imprint Academic.

Bourdieu, P. (1979). La Distinction. Critique sociale du jugement. Paris: Éditions de Minuit.

Bourdieu, P. (1996). As regras da arte: gênese e estrutura do campo literário. São Paulo: Companhia das Letras.

Colardelle, M. (1999). Exist'il encore une art populare. L'Art c'est l'art. Neuchatel, 231-44.

Delacampagne, C. (1989). Outsiders: fous, naïfs et voyants dans la peinture moderne (1880-1960). Paris: Mengès.

Dubufett, J. (1964). Préface. L’Art Brut, fascicule 1, Paris, 3-5.

Dubufett, J. (1999). L'homme du commun a l'ouvrage. Paris: Galimard. 
Frota, L. C. (1978). Mitopoética de 9 artistas brasileiros. Rio de Janeiro: FUNARTE.

Iphan (2016). Tombamento da Casa da Flor, em São Pedro da Aldeia (RJ), é aprovado por unanimidade. Portal do IPHAN, 15 de setembro de 2016. Recuperado de: http://portal.iphan.gov.br/rj/noticias/detalhes/3809/tombamento-da-casa-da-flor-em-sao-pedroda-aldeia-rj-e-aprovado-por-unanimidade

Lassus, B. (1975). Les habitants-paysagistes. Revue d'Esthétique, 2 (3-4), 227-249.

Lommel, M. (2004). L’Aracine et l'art brut. Neuilly-Plaisance: G. Michon.

Maizels, J. (2007). Fantasy worlds. Schaewen, D. (Photos); Taschen, A. (ed.). Köln: Taschen GmbH.

Ortiz, R. (1985). Cultura popular. São Paulo: PUC.

Peiry, L. (1997). L’Art Brut. Paris: Flamarion.

Ragon, M. (1983). Préface. In Boubonnais, A. (org). La fabuloserie : art hors les normes, art brut (DicyYonne). (1-15). Paris: SMI.

Shapiro, R. (2007). Que é artificação? Sociedade e Estado, 22(1), 135-151.

Sousa, E. (1973). Para o estudo da escultura portuguesa. 2 ed. Lisboa: Livros Horizonte.

Thévoz, M. (1980). L'Art Brut. Genève: Editions d'Art Albert Skira.

Thévoz, M. (1997). Preface. In Peiry, L. Art brut. (pp. 7-8) Paris: Flammarion.

Weiss, A. (1993). Nostalgia for the absolute: obsession and Art Brut. In Tuchman, Maurice and Eliel, Carol (orgs). Parallel Visions: modern artist and outsider art. (pp. 280-295) Exhibition organized by the Los Angeles Country Museum of Art, oct. 1992-jan. 1993. Los Angeles/Princeton: Princeton University Press.

Zaluar, A. (1997). A Casa da Flor: uma arquitetura poética. Revista do Patrimônio Histórico e Artístico Nacional. Rio de Janeiro, 25. 